\title{
Les femmes des Balkans sous L'Occupation
}

Joëlle Dalègre

\section{OpenEdition}

Journals

Édition électronique

URL : https://journals.openedition.org/ceb/3950

DOI : $10.4000 /$ ceb.3950

ISSN : 2261-4184

Éditeur

INALCO

Édition imprimée

Pagination : 219-220

ISBN : 978-2-85837-205-4

ISSN : 0290-7402

\section{Référence électronique}

Joëlle Dalègre, «Les femmes des Balkans sous L'Occupation », Cahiers balkaniques [En ligne], 41

2013, mis en ligne le 19 mai 2013, consulté le 06 juillet 2021. URL : http://journals.openedition.org/ ceb/3950 ; DOl : https://doi.org/10.4000/ceb.3950

Ce document a été généré automatiquement le 6 juillet 2021.

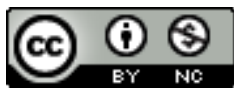

Cahiers balkaniques est mis à disposition selon les termes de la Licence Creative Commons Attribution - Pas d'Utilisation Commerciale 4.0 International. 


\title{
Les femmes des Balkans sous L'Occupation
}

\author{
Joëlle Dalègre
}

\section{NOTE DE L'ÉDITEUR}

Colloque International des 9 et 10 décembre 2011 à l'INALCO.

Organisé par la section de grec moderne, le Centre d'Études Balkaniques et le Centre d'Études Europes - Eurasie de l'INALCO ainsi que par le Centre grec de recherches en sciences sociales (EKKE) et les Archives d'Histoire Sociale Contemporaine (ASKI) avec le soutien du Ministère de l'Éducation Nationale et de la Culture de Chypre.

1 Les études de genre, initiées dans le monde anglo-saxon à partir des années 1970 ont mis en avant la spécificité du rôle des femmes, jusqu'alors "oubliées de l'histoire ", dans les changements historiques, sociaux et politiques. Si l'expérience des Françaises dans les deux guerres mondiales a déjà fait l'objet de nombreuses études, le traitement des discours et des pratiques relatives aux femmes des Balkans dans les années 1940, constitue un champ de recherche en pleine expansion. Le colloque, Femmes des Balkans sous l'occupation, a permis par un éclairage pluridisciplinaire, de mettre en exergue les réalités et contrastes des espaces balkaniques. Les femmes des Balkans se sont trouvées dans des situations économiques, politiques, idéologiques, sociales exceptionnelles, même si l'historiographie officielle, encore très accaparée par les études militaires et politiques, les a jusqu'ici négligées.

2 Le colloque s'est tenu les 9 et 10 décembre 2011 à l'INALCO, suivi, le lendemain, décembre Table ronde sur l'expression testimoniale des années 1940 en Grèce. Ont participé à l'événement (ordre des interventions) Danielle Voldman (CNRS), Maria Thanopoulou (EKKE, Athènes), Ioanna Papathanassiou (EKKE, ASKI, Athènes), Odette Varon-Vassard (Université grecque ouverte, Athènes), Krassimira Daskalova (Saint Clément d'Ochrid, Bulgarie \& Graduate School of Social Sciences, Hitotsubashi University, Japon), Ivana Pantelic (Université de Belgrade, Serbie), Christina 
Alexopoulos (INALCO), Maria Couroucli (CNRS, LESC, Paris X-Nanterre, École Française d'Athènes), Georges Kostakiotis (INALCO), Bernard Lory (INALCO), Hélène Lenz (Strasbourg II), Joëlle Dalègre (INALCO), Tasoula Vervenioti (Université grecque ouverte), Lidya Mihova (Strasbourg II), Frosa Pejoska-Bouchereau (INALCO).

3 Le Colloque a été suivi par la projection du documentaire témoignage (sous-titré

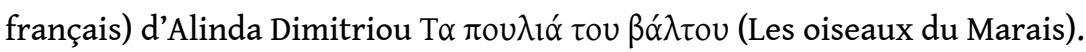

4 On trouvera dans ce numéro les contributions de Joëlle Dalègre (Femmes de Lia -Épireentre 1935 et 1948), Hélène Lenz (Quand une femme écrit en homme), Ivana Pantelic (Yugoslav female partisans in World War II) et Maria Thanopoulou (À la recherche de la mémoire des Femmes dans la Guerre). 